\title{
Comparative Evaluation of Dentin Removal and Taper of Root Canal Preparation of Hand K File, ProTaper Rotary File, and Kedo S Rotary File in Primary Molars Using Cone-beam Computed Tomography
}

\author{
Thakur Seema $^{1}$, Haseeb Ahammed ${ }^{2}$, Singhal Parul ${ }^{3}$, Jayam Cheranjeevi ${ }^{4}$
}

\begin{abstract}
Various rotary endodontic instruments were used and studied for the root canal preparation of the primary teeth. Recently, a new venture evolved in the field of pediatric endodontic, which was Kedo $\mathrm{S}$ rotary files. These are the files designed exclusively for root canal preparation of the primary teeth.

Aim: The study aimed to comparatively evaluate the dentin removal and taper of root canal preparation of Hand K files, Rotary Prosper files, and Rotary Kedo $S$ files using cone-beam computed tomography (CBCT) and instrumentation time using stopwatch in primary molars.

Materials and methods: Sixty-three root canals of maxillary and mandibular primary molars were included in the study. The root canals were randomly assigned to Hand K file (group I), Rotary ProTaper file (group II), and Rotary Kedo S file (group III). Dentin removal and taper of the root canal preparations were evaluated by using CBCT.

Results: All the three file systems do not show any statistical significant differences at middle third and apical third but at coronal third, Kedo $\mathrm{S}$ removed significantly less amount of dentin as compared to the Hand K file. Taper of the preparations did not show significant differences, even though the rotary files showed good taper in maximum number of root canals.

Conclusion: Although not much statistical significant differences were observed in our study, the rotary file system performed slightly better in root canal preparations in primary molars.
\end{abstract}

Keywords: Hand K file, Kedo S rotary file, ProTaper rotary file, Taper of root canal preparation.

International Journal of Clinical Pediatric Dentistry (2020): 10.5005/jp-journals-10005-1787

\section{INTRODUCTION}

As that of permanent tooth, in primary tooth the biological and mechanical preparation of the root canal is one of the important steps for removal of microbes and debris from the root canal in order to achieve a high-level success of the endodontic treatment. ${ }^{1}$ Various procedural errors have arisen during biomechanical preparation of the root canals such as perforations, ledge formation, transportation of canal, formation of cracks in the root dentin, and improper taper of the canal preparation. ${ }^{2}$ Along with these errors, another important factor to keep in mind during the root canal procedure is dentin thickness of the root canal. ${ }^{3}$ Effective enlargement with maintenance of the original anatomy, at the same time preservation of the maximum dentin thickness, is generally recommended during instrumentation in root canals. ${ }^{4}$

Introduction of the nickel-titanium rotary files into the pediatric endodontics by Barr et al. revolutionized the root canal procedure in the primary tooth. ${ }^{5}$ After that, various studies reported in the literature regarding the use of rotary endodontic files for the root canal preparation in the primary tooth. Among the various rotary file systems, the ProTaper file system is widely used and studied. ${ }^{6}$ Even though until 2016 no files were available exclusively for the preparation of the root canals of primary teeth, the files that were used to prepare the permanent tooth was also used in primary dentition. Invention of Kedo S files, an exclusive rotary endodontic files for primary teeth, was a new venture in the field of pediatric dentistry, more specifically pediatric endodontics. The Kedo S file
${ }^{1-4}$ Department of Pedodontics and Preventive Dentistry, HP Government Dental College and Hospital, Shimla, Himachal Pradesh, India

Corresponding Author: Thakur Seema, Department of Pedodontics and Preventive Dentistry, HP Government Dental College and Hospital, Shimla, Himachal Pradesh, India, Phone: +91 9418470915, e-mail: cima2009@hotmail.com

How to cite this article: Seema T, Ahammed H, Parul S, et al. Comparative Evaluation of Dentin Removal and Taper of Root Canal Preparation of Hand K File, ProTaper Rotary File, and Kedo S Rotary File in Primary Molars Using Cone-beam Computed Tomography. Int J Clin Pediatr Dent 2020;13(4):332-336.

Source of support: Nil

Conflict of interest: None

system consists of three different diameter $\mathrm{Ni}-\mathrm{Ti}$ rotary files. Each file is having a total length of $16 \mathrm{~mm}$ and $12 \mathrm{~mm}$ of working length with varying taper. Few studies have been reported in the literature comparing the efficacy of the Kedo S file to the hand file system in primary teeth. ${ }^{7}$

Researchers used various methods such as radiography, histlogical section, electron microscopy, computed tomography (CT), cone-beam CT (CBCT), micro CT, and stereomicroscopy to assess the shaping abilities of the endodontic instruments. Currently, CBCT has been widely used for noninvasive evaluation of prepared root canals by endodontic instrument. ${ }^{8}$ 
The purpose of this research is to find a better root canal instrumentation system in primary teeth; the present study is designed to comparatively evaluate the dentin removal and taper of the root canal preparation of the Hand $K$ file, the ProTaper rotary file, and the Kedo $S$ rotary file in primary maxillary and mandibular molars by using CBCT.

\section{Materials and Methods}

The present in vitro study is a randomized comparative study conducted in the pediatric dental department of HPGDC, Shimla, Himachal Pradesh. The study was done on 63 primary molar root canals. The selection of the root canals was done on the basis of certain predetermined criteria, which included primary molar roots having two-third of their remaining root length without any evidence of external/internal resorption. Calcification and internal resorption were determined and confirmed with preoperative anatomic images obtained by CBCT.

All the teeth were arranged on the modeling wax (Rolex, India), which was horseshoe-shaped to accommodate in the similarly shaped scanning tray of the CBCT machine (Genoray Papaya 3d, Korea). This custom-made wax sheet (modeling wax) was constructed with the dimension less than the field of view (FOV) of the CBCT machine.

Each wax model was then submitted to the CBCT examination. This prepared model was placed in a horseshoe-shaped tray of the CBCT machine and positioning laser light was adjusted accordingly. The FOV of the machine was set as $8 \mathrm{~cm} \times 8 \mathrm{~cm}$ with resolution of $75 \mu \mathrm{m}$ and images of the specimens were taken with exposure parameters $90 \mathrm{kV}, 8 \mathrm{~mA}$, and 7.7 seconds.

After initial removal of caries, the access cavity was made by no. 4 round bur (Mani, Japan). The access cavity's roof was removed using safe-ended diamond-tapered fissure bur (Mani, Japan) with outward brushing motion. After irrigation of the pulp chamber with $3 \%$ sodium hypochlorite (Hyposol, India), no. $10 \mathrm{~K}$-file (SSMani, Japan) was introduced manually into the root canal until just visible at the apical foramen and $1 \mathrm{~mm}$ short of this initial length was recorded as working length for the root canal preparation. After the working length determination, instrumentation was started.

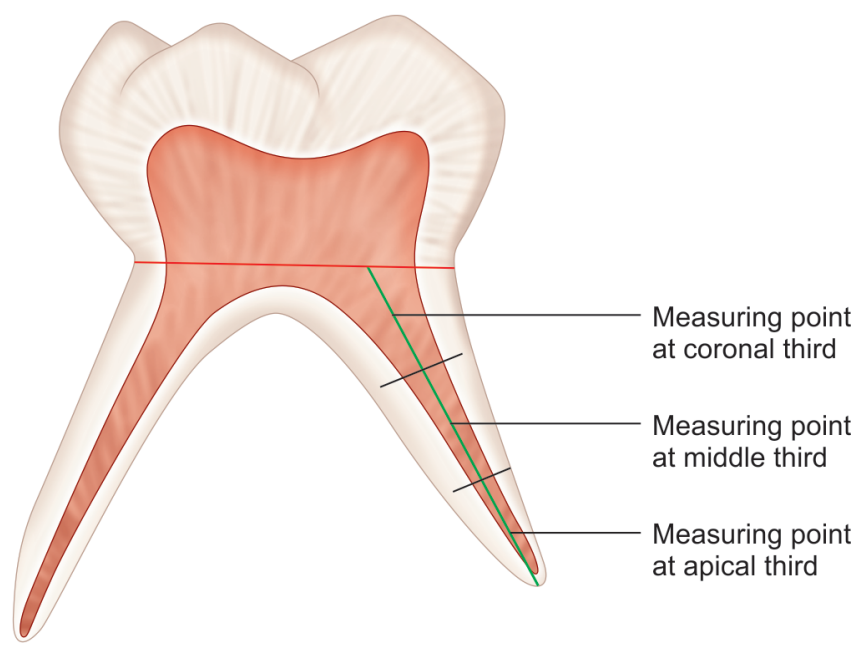

Fig. 1: Measuring points at three levels
Group I: A total of 21 root canals were prepared with the Hand K file (SS-Mani, Japan). Each canal was prepared with the step back technique.

Group II: A total of 21 root canals were prepared with ProTaper universal S2 (Dentsply, USA) file till the working length using the $\mathrm{X}$ smart endomotor (Dentsply, USA) with $1.4 \mathrm{~N} \mathrm{~cm}$ torque and 300 rpm speed in lateral brushing motion with regular irrigation with $3 \% \mathrm{NaOCl}$ followed by normal saline in between.

Group III: A total of 21 root canals were prepared with the Kedo S file (Reegans Dental Care, India) file till the working length using the $\mathrm{X}$ smart endomotor (Dentsply, USA). For narrow canals like mesiobuccal and mesiolingual canals of primary mandibular molar, mesiobuccal and distobuccal canals of primary maxillary molar were prepared with the D1 Kedo S file. The distal canal of primary mandibular and the palatal canal of maxillary molar were prepared with the E1 file. The torque and speed were set as $2.2-2.4 \mathrm{~N} \mathrm{~cm}$ and 250-300 rpm, respectively, in lateral brushing motion.

Irrigation of the root canals was done with $3 \%$ sodium hypochlorite followed by normal saline.

Dentin removal was measured at three different levels, coronal third, middle third, and apical third, in mesial and distal surfaces of root. Measuring points at each level were assessed by drawing an imaginary line connecting the cementoenamel junction, and this was used as a reference line in coronal and sagittal sections. Distance between this line and apex of the root was measured through the center of canal orifice and it was recorded as total root length. This root length was divided into three halves, each as coronal third, middle third, and apical third after this; each half was further divided into two, for the measurement of the dentin removal (Fig. 1).

A formula $A 1-A 2$ is used for the assessment of the dentin removal of the mesial side of root after the root canal preparation. Where $\mathrm{A} 1$ is the shortest distance between the canal's mesial periphery and root's mesial periphery of the noninstrumented canal in the axial section and $A 2$ is the shortest distance between the canal's mesial periphery and root's mesial periphery of the instrumented canal in axial sections (Fig. 2). The formula B1-B2 is used for the assessment of the dentin removal of the distal side after the root canal preparation. B1 is the shortest distance between the canal's distal periphery and root's distal periphery

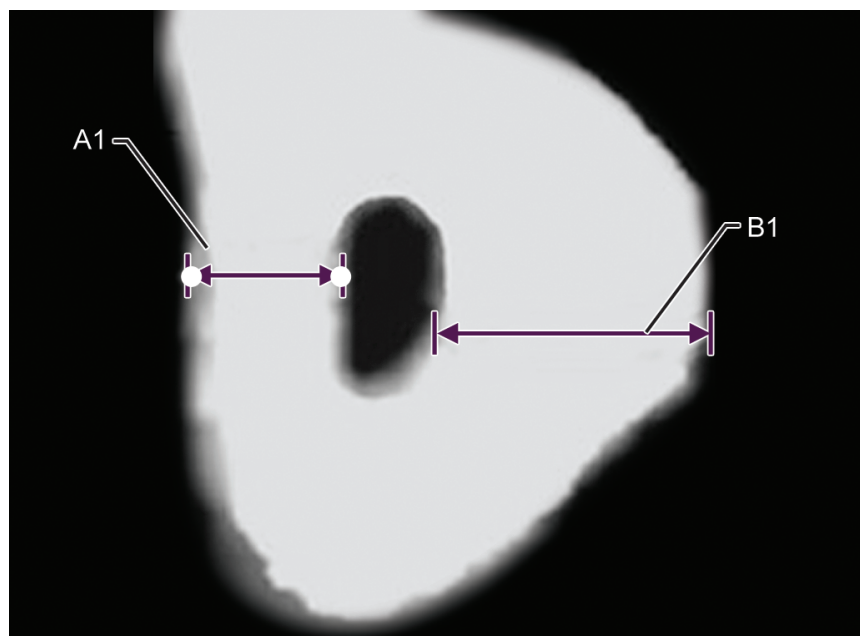

Fig. 2: Axial section showing the $A 1$ and $B 1$ measurements 
of the noninstrumented canal, and B2 is the shortest distance between the canal's distal periphery and root's distal periphery of the instrumented canal in axial sections (Fig. 3).

Taper of the root canal preparation was evaluated from the post-instrumentation $\mathrm{CBCT}$ images. The maximum mesiodistal diameter was measured at center of coronal third, middle third, and apical third (Fig. 4), and root canal preparations were assessed as good or poor taper.

Progressive reduction of the mesiodistal diameter from the coronal, middle, to apical third was considered as good taper, and either the same or increase in the reading of the mesiodistal diameter from the coronal, middle, to apical third was recorded as poor taper. ${ }^{9}$

\section{Statistical Analysis}

The statistical analysis was done by using the Statistical Package for the Social Sciences (SPSS) version 20.0 (SPSS Inc., Chicago, IL, USA) for MS Windows. $p<0.05$ was considered statistically significant.

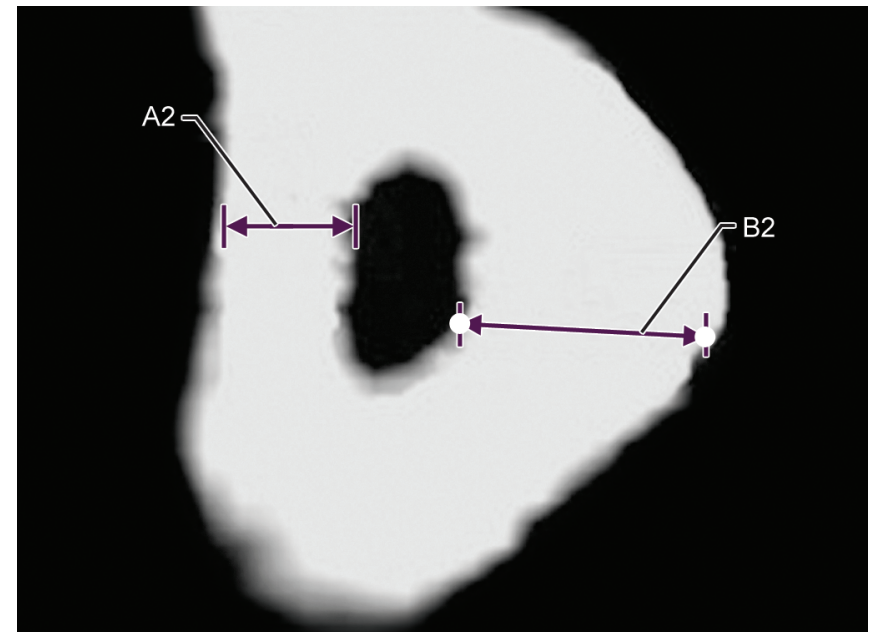

Fig. 3: Axial section showing the $A 2$ and $B 2$ measurements
The independent $t$ test and ANOVA test were used to determine any statistical significant difference in dentin removal between two groups and three groups combined, respectively.

The Chi-square test was carried out to determine if there is any significant difference between the scores of the taper of root canal preparation among three groups.

\section{Results}

In the mesial surface of group I, average amount of dentin removed is significantly more than group III at coronal third, whereas at all other levels it does not showed any statistical significant differences between three groups. In the distal surface, there were no significant differences between three groups at all the three levels (Tables 1 and 2).

Comparison of the taper of root canal preparation showed that all three groups frequently showed good taper of prepared root canal, with statistically no significant difference among them (Table 3).

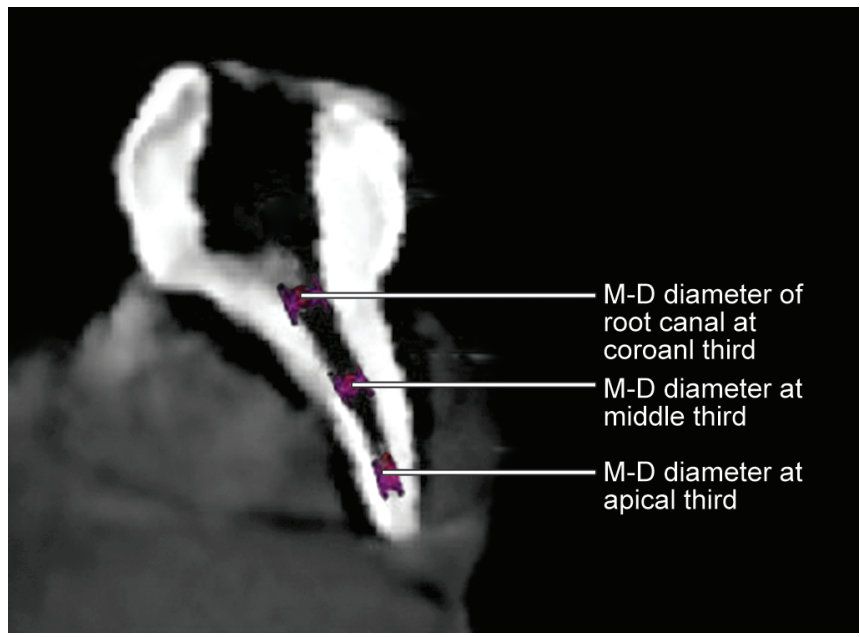

Fig. 4: Measurement of mesiodistal diameter of root canal at three points

Table 1: Mean comparisons of dentin removal between group I, group II, and group III at coronal third, middle third, and apical third on the mesial side

\begin{tabular}{|c|c|c|c|c|c|c|c|}
\hline & Group I & Group II & Group III & & & & pvalue \\
\hline Variables & Mean $\pm S D$ & Mean $\pm S D$ & Mean $\pm S D$ & $\Delta_{1}, p$ value & $\Delta_{2}, p$ value & $\Delta_{3} p$ value & (ANOVA test) \\
\hline Coronal third & $0.31 \pm 0.21$ & $0.24 \pm 0.10$ & $0.19 \pm 0.10$ & $0.07 \pm 0.11, p=0.157$ & $0.12 \pm 0.11, p=0.020^{*}$ & $0.05 \pm 0.00, p=0.115$ & $0.029 *$ \\
\hline Middle third & $0.23 \pm 0.09$ & $0.20 \pm 0.08$ & $0.18 \pm 0.07$ & $0.03 \pm 0.01, p=0.377$ & $0.05 \pm 0.02, p=0.098$ & $0.02 \pm 0.01, p=0.382$ & 0.226 \\
\hline Apical third & $0.16 \pm 0.08$ & $0.18 \pm 0.09$ & $0.23 \pm 0.22$ & $0.02 \pm 0.01, p=0.422$ & $0.07 \pm 0.14, p=0.204$ & $0.05 \pm 0.13, p=0.405$ & 0.334 \\
\hline
\end{tabular}

Statistical analysis: independent sample $t$ test and ANOVA one-way test. $p<0.05$ : statistically significant

$\Delta_{1}$ : mean and SD difference between group I and group II

$\Delta_{2}$ : mean and SD difference between group I and group III

$\Delta_{3}$ : mean and SD difference between group II and group III

Table 2: Mean comparisons of dentin removal between group I, group II, and group III at coronal third, middle third, and apical third on the distal side

\begin{tabular}{|c|c|c|c|c|c|c|c|}
\hline & Group I & Group II & Group III & & & & pvalue \\
\hline Variables & Mean $\pm S D$ & Mean $\pm S D$ & Mean $\pm S D$ & $\Delta_{1}, p$ value & $\Delta_{2}, p$ value & $\Delta_{3}, p$ value & (ANOVA test) \\
\hline Coronal third & $0.21 \pm 0.11$ & $0.22 \pm 0.06$ & $0.26 \pm 0.12$ & $0.01 \pm 0.05, p=0.791$ & $0.05 \pm 0.01, p=0.249$ & $0.04 \pm 0.06, p=0.249$ & 0.364 \\
\hline Middle third & $0.19 \pm 0.09$ & $0.24 \pm 0.15$ & $0.18 \pm 0.06$ & $0.05 \pm 0.06, p=0.284$ & $0.01 \pm 0.03, p=0.570$ & $0.06 \pm 0.09, p=0.123$ & 0.228 \\
\hline Apical third & $0.15 \pm 0.06$ & $0.15 \pm 0.06$ & $0.19 \pm 0.08$ & $0.00 \pm 0.00, p=1.000$ & $0.04 \pm 0.02, p=0.079$ & $0.04 \pm 0.02, p=0.084$ & 0.107 \\
\hline
\end{tabular}

Statistical analysis: independent sample $t$ test and ANOVA one-way test. $p<0.05$ : statistically significant

$\Delta_{1}$ : mean and SD difference between group I and group II

$\Delta_{2}$ : mean and SD difference between group I and group III

$\Delta_{3}$ : mean and SD difference between group II and group III 
Table 3: Comparison of root canal preparation between group I, group II, and group III

\begin{tabular}{lllll}
\hline Taper & Sample size & Group I & Group II & Group III \\
\hline Poor & $N$ & 6 & 3 & 4 \\
& $\%$ & 28.5 & 14.3 & 19.04 \\
Good & $N$ & 15 & 18 & 17 \\
& $\%$ & 71.4 & 85.7 & 80.95 \\
Total & $N$ & 21 & 21 & 21 \\
& $\%$ & 100.0 & 100.0 & 100.0 \\
\hline
\end{tabular}

Chi-square value $=1.356 ; p$ value $=0.507 ; \mathrm{NS}$

Statistical analysis: Chi-square test. Statistically significant if $p<0.05$

Intraobserver and interobserver reliability were calculated by reexamination of random 21 values. Intraobserver reliability showed almost perfect agreement whereas interobserver reliability indicated that at substantial level it shows almost perfect agreement.

\section{Discussion}

Adequate amount of remain dentin thickness is necessary for providing enough resistance for an endodonticallly treated tooth to lateral and occlusal forces. ${ }^{10} \mathrm{~A}$ positive correlation is present between the aggressiveness of the root canal instrument and amount of dentin removal. ${ }^{11}$

Especially in primary tooth if the remain dentin thickness is reduced after root canal instrumentation, it hastens the exfoliation of the tooth.

On the mesial side, no significant difference in the amount of dentin is removed between the Hand $\mathrm{K}$ file and rotary ProTaper files at all the three levels. In the same way, no significant difference was observed between the Hand K file and rotary Kedo S file at middle third and apical third, but at the coronal third the Hand K file removed significantly more dentin as compared to the Kedo S file. On the distal side, all the three file system removed almost equal amount of dentin without statistical significant results.

In a study by Kummer et al., it was observed that except at the apical third, manual instrumentation removed more dentin as compared to rotary instrumentation. ${ }^{12}$ This study shows some similarity with our findings that in our comparison also Hand $\mathrm{K}$ files showed more dentin removal at coronal third. Musale et al. conducted a comparative assessment of dentin removal between the Hand $\mathrm{K}$ file and the 0.04 hero shaper classic file in primary molars. Their observation revealed that at all three levels Hand $\mathrm{K}$ file removed significantly more dentin as compared to 0.04 rotary 0.04 hero shaper. $^{10}$

According to Schilders, the mechanical objective of the root canal preparation is to develop a continuously tapering cone. ${ }^{13}$ This is important in root canal preparation of the primary teeth also, because it allows the admirable placement of the obturating material. Design of the instrument and initial shape of the canal are two main factors responsible for the taper of root canal preparation. In our study, the three groups did not show any statistical significant results in taper of root canal preparation; however, the $85.7 \%$ of rotary ProTaper and $80.95 \%$ of Kedo $S$ preparations showed better taper, but only $71.4 \%$ of hand preparation came as good preparation. Instrument design of the Hand $\mathrm{K}$ files and rotary files follows the tapering cone. These statistically insignificant results can be justified by these design features and initial shape of the canal itself.
Nagaratna et al. compared the taper of preparations of the Hand K file and profile 0.04-taper 29 series. ${ }^{14}$ Their findings showed a comparable difference in terms of taper among two groups in mesiobuccal and mesiolingual canals of mandibular molars; meanwhile, rotary files showed a significantly better taper of preparation than Hand $\mathrm{K}$ files.

Musale et al. evaluated the taper of the preparation among hand files and rotary files using CBCT. They compared Hand K file and four different types of rotary files including ProTaper files. Even though their observation have shown that ProTaper has high frequency of good taper of preparation, but contrary to our findings their results were statistically significant. Nahid Razani compared the Hand $\mathrm{K}$ files with $\mathrm{m}$-two rotary files using CBCT for the evaluation and they found almost similar observations as Muslae et al., that the taper of the preparation was significantly good in rotary files as compared to Hand K files. ${ }^{9,15}$

\section{Conclusion}

Within the experimental conditions of the present study, the following conclusions can be drawn:

- All the three file systems do not show any statistical significant differences at middle third and apical third but at coronal third Kedo $S$ removed significantly less amount of dentin as compared to the Hand K file on the mesial side and on the distal side all the three file systems performed almost similarly.

- Taper of the preparations did not show significant differences, even though the rotary files showed good taper in maximum number of root canals.

\section{References}

1. Peters $O A$. Current challenges and concepts in the preparation of root canal systems: A review. J Endod 2004;30(8):559-567. DOI: 10.1097/01. DON.0000129039.59003.9D.

2. Blum JY, Machtou P, Ruddle C, et al. Analysis of mechanical preparations in extracted teeth using ProTaper rotary instruments: Value of the safety quotient. J Endod 2003;29(9):567-575. DOI: 10.1097/00004770-200309000-00007.

3. Pasqualini D, Scotti N, Tamagnone L, et al. Hand-operated and rotary ProTaper instruments: A comparison of working time and number of rotations simulated root canals. J Endod 2008;34(3):314-317. DOI: 10.1016/j.joen.2007.12.017.

4. Grande NM, Plotino G, Pecci R, et al. Micro-computerized tomographic analysis of radicular and canal morphology of premolars with long oval canals. Oral Surg Oral Med Oral Pathol Oral Radiol Endod 2008;106(3):e70-e76. DOI: 10.1016/j.tripleo.2008.04.022.

5. Barr ES, Kleier DJ, Barr NV. Use of nickel-titanium rotary files for root canal preparation in primary teeth. Pediatr Dent 2000;22(1):77-78.

6. Kuo $\mathrm{Cl}$, Wang $\mathrm{YL}$, Chang $\mathrm{HH}$, et al. Application of Ni-Ti rotary files for pulpectomy in primary molars. J Dent Sci 2006;1:10-15.

7. Jeevanandan G. Kedo $S$ paediatric rotary files for root canal preparation in primary teeth - case report. J Clin Diagn Res 2017;11(3):3-5. DOI: 10.7860/JCDR/2017/25856.9508.

8. Shah DY, Waldekar SI, Dapde AM, et al. Canal transportation and cenetring ability of ProTaper and self adjusting file system in long oval canals: An ex vivo cone beam computed tomography analysis. J Conserv Dent 2017;20(2):105-109. DOI: 10.4103/0972-0707.212234.

9. Musale PK, Mujawar SA. Evaluation of the efficacy of rotary versus hand files in root canal preparation of primary teeth in vitro using CBCT. Eur Arch Paediatr Dent 2014;15(2):113-120. DOI: 10.1007/s40368013-0072-1.

10. Musale PK, Jain KR, Kothare SS. Comparative assessment of dentin removal following hand and rotary instrumentation in primary molars 
using cone-beam computed tomography. J Indian Soc Pedod Prev Dent 2019;37(1):80-86. DOI: 10.4103/JISPPD.JISPPD_210_18.

11. Lim SS, Stock CJ. The risk of perforation in the curved canal: Anticurvature filing compared with the stepback technique. Int Endod J 1987;20(1):33-39. DOI: 10.1111/j.1365-2591.1987.tb00586.x.

12. Kummer TR, Calvo MC, Cordeiro MM, et al. Ex vivo study of manual and rotary instrumentation techniques in human primary teeth. Oral Surg. Oral Med. Oral Pathol. Oral Radiol. Endod. 2008;105(4):84-92. DOI: 10.1016/j.tripleo.2007.12.008.

13. Schilder $\mathrm{H}$. Cleaning and shaping of root canal. Dent Clin North Am 1974;18(2):269-296.
14. Nagaratna PJ, Shashikiran ND, Subbareddy VV. In vitro comparison of $\mathrm{Ni}$-Ti rotary instruments and stainless steel hand instruments in root canal preparations of primary and permanent molar. J Indian Soc Pedod Prev Dent 2006;24(4):186-191. DOI: 10.4103/0970-4388. 28075.

15. Ramzani N, Mohammed A, Amirabadi F, et al. In vitro investigation of the cleaning efficacy, shaping ability, preparation time and file deformation of continuous rotary, reciprocating rotary and manual instrumentation in primary molars. J Dent Res Dent Clin Dent 2016;10(1):49-56. DOI: 10.15171/joddd.2016. 008. 